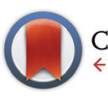

CrossMark \&lick for updates

Cite this: Dalton Trans., 2016, 45 10708

Received 16th May 2016

Accepted 31st May 2016

DOI: 10.1039/c6dt01947a

www.rsc.org/dalton

\title{
On the importance of tetrel bonding interactions in lead(II) complexes with (iso)nicotinohydrazide based ligands and several anions $\uparrow$
}

\author{
Ghodrat Mahmoudi, ${ }^{\star a}$ Antonio Bauzá, ${ }^{\mathrm{b}}$ Mojtaba Amini, ${ }^{a}$ Elies Molins, ${ }^{c}$ Joel T. Mague ${ }^{\mathrm{d}}$ \\ and Antonio Frontera*b
}

\begin{abstract}
Four $\mathrm{Pb}($ II) complexes of (iso)nicotinohydrazide-based ligands and different anionic coligands (azide, nitrate, acetate and iodide) have been synthesized and characterized by structural, analytical and spectroscopic methods. The mono-deprotonated or neutral forms of the ligands coordinate in a tridentate fashion via two nitrogen and one oxygen donor atoms to the $\mathrm{Pb}$. Single-crystal X-ray crystallography showed that the molecular complexes can aggregate into larger entities depending upon the anion coordinated to the metal centre. In all four complexes the lead center is hemidirectionally coordinated and, consequently, it is sterically ideal for establishing tetrel bonding interactions. In the crystal structures of all complexes, the lead atoms participate in short contacts with nitrogen atoms. These contacts are shorter than the sums of the van der Waals radii and larger than the sums of the covalent radii. The tetrel bonding interactions interconnect the covalently bonded units (monomers or dimers) into supramolecular assemblies (chains and 3D structures). We have analysed the interesting supramolecular assemblies observed in the solid state of all four complexes by means of DFT calculations.
\end{abstract}

\section{Introduction}

Metal-organic frameworks (MOFs) are continuously attracting the attention of chemists working in crystal engineering, solidstate and materials chemistry due to their promising applications in multidisciplinary fields like photoluminescence and electronics, magnetism, gas absorption, and many others. ${ }^{1}$ Nowadays, it is possible to modify and tune the properties of MOFs by using different ligands, ${ }^{2}$ metal centres with different coordination behaviour, ${ }^{3}$ and counter ions. ${ }^{4}$ More importantly, it is also possible to modulate their properties using supramolecular interactions. ${ }^{5}$

Apart from the widely used hydrogen bonding interactions for the construction/modification of MOFS, other specific noncovalent interactions like $\sigma$-hole interactions, especially halogen bonds, are becoming prominent players. ${ }^{6}$ Halogens,

\footnotetext{
${ }^{a}$ Department of Chemistry, Faculty of Science, University of Maragheh, P.O. Box 55181-83111, Maragheh, Iran.E-mail: mahmoudi_ghodrat@yahoo.co.uk ${ }^{b}$ Departamento de Quimica, Universitat de les Illes Balears, Crta. de Valldemossa km 7.5, 07122 Palma de Mallorca, Baleares, Spain. E-mail: toni.frontera@uib.es ${ }^{c}$ Institut de Ciència de Materials de Barcelona (ICMAB-CSIC), Campus de la Universitat Autònoma de Barcelona, 08193 Bellaterra, Spain

${ }^{d}$ Department of Chemistry, Tulane University, New Orleans, LA 70118, USA $\dagger$ Electronic supplementary information (ESI) available: Tables S1-S4 and Fig. S1-S3. CCDC 1474989 and 1480033-1480035. For ESI and crystallographic data in CIF or other electronic format see DOI: 10.1039/c6dt01947a
}

however, are not the only atoms susceptible to formation of $\sigma$-holes. ${ }^{7}$ Electron-deficient regions are also present on covalently bonded heavier atoms of groups IV to VII and are located in the extension of the covalent bond. The size and electron deficiency of $\sigma$-holes increases with increasing electron-withdrawing nature of the covalently bonded group and with the polarizability of the atom on which the $\sigma$-hole is formed. The strongest $\sigma$-hole interactions occur in systems where a heavy atom of groups IV to VII is covalently bonded to electronegative ones. Although $\sigma$-hole interactions have been widely described for groups VI (chalcogen interaction) and $\mathrm{V}$ (pnictogen interaction), those of group IV (tetrel interaction) are scarce, ${ }^{8}$ However, it has been shown that they can be markedly strong, in particular with $\mathrm{Sn}$ and $\mathrm{Pb}$, the metallic members of the group. Previously some of us have reported the design and synthesis of lead(II) metal-organic frameworks (MOFs) based on covalent and noncovalent tetrel bonding. ${ }^{9}$ In these MOFs, $\mathrm{Pb} \cdots \mathrm{S}$ and $\mathrm{Pb} \cdots \mathrm{N}$ noncovalent tetrel bonds interconnect the covalently bonded units into supramolecular assemblies. A combined DFT study and a statistical survey of the Cambridge Structural Database (CSD) revealed that tetrel bonds with hemidirectionally coordinated lead occur with high probability and with predictable geometries, thus playing an important role in the solid-state chemistry of lead. Moreover, we have recently shown that concurrent noncovalent tetrel bonding, agostic interactions and chelate ring-chelate 

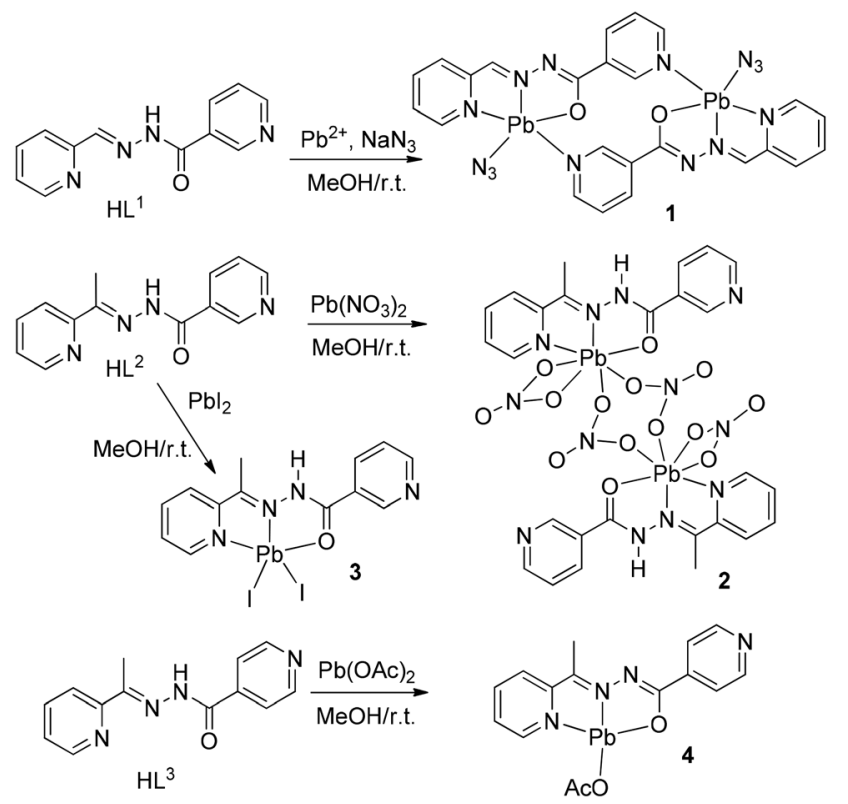

Scheme 1 Synthetic route to complexes 1-4.

ring stacking interactions control the supramolecular architectures and organometallic frameworks observed in the solid state architecture of hemidirectionally coordinated $\mathrm{PbX}_{2}$ salts (X $=\mathrm{Cl}, \mathrm{NO}_{2}$, I and SCN) to the $N^{\prime}$-(phenyl(pyridin-2-yl)methylene)-isonicotinohydrazide ligand. ${ }^{10}$

Taking advantage of this understanding, herein we report the synthesis and X-ray characterization of four new $\mathrm{Pb}$ (II) complexes with (iso)nicotinohydrazide-based ligands and different anions (azide, nitrate, acetate and iodine) as coligands (see Scheme 1). Interestingly, in all complexes the $\mathrm{Pb}$ (II) is hemidirectionally coordinated and participates in noncovalent tetrel bonding interactions. These forces along with stacking interactions control the supramolecular architectures and organometallic frameworks observed in their solid state architecture. In line with previous reports, the $\mathrm{Pb}^{2+}$ shows a tendency to establish an unusual coordination mode in which the $\mathrm{Pb}^{2+}$ ion has a clear void in the distribution of bonds to the ligands (hemidirectional coordination). ${ }^{11}$ Such void in the coordination sphere facilitates the approach of electron donors to the $\sigma$-hole of the $\mathrm{Pb}^{2+}$ enabling the formation of a strong tetrel bond with a more predictable geometry. The nature of the tetrel bonds in all four structures was studied by DFT calculations, which showed the presence of the $\sigma$-hole at the $\mathrm{Pb}$ atom and the considerable strength of these interactions.

\section{Experimental}

\subsection{Materials and methods}

All reagents used in these studies were obtained from commercial sources and used as received. The ligands $\mathrm{HL}^{1}, \mathrm{HL}^{2}$ and $\mathrm{HL}^{3}$ were prepared using the procedure previously described. ${ }^{12}$ Briefly, they were obtained by the condensation of either 2-acetylpyridine or 2-formylpyridine with (iso)nicotinohydrazide in ethanol solution. Recrystallization from aqueous $\mathrm{EtOH}$ afforded pure ligands in $>80 \%$ yield.

Elemental analyses were carried out using an Elemental Vario EL III instrument and FT-IR spectra were recorded on a Bruker Tensor 27 FT-IR spectrometer with $\mathrm{KBr}$ disks in the range 4000-400 $\mathrm{cm}^{-1}$. Caution! Lead and its compounds are toxic. ${ }^{13}$ Only a small amount of these materials should be prepared and handled with care.

\subsection{Synthesis of $\left[\mathrm{Pb}_{2}\left(\mathrm{~L}^{1}\right)_{2}\left(\mathrm{~N}_{3}\right)_{2}\right](1)$}

To a magnetically stirred solution of 2-formyl-pyridyl-nicotinoylhydrazone $(0.113 \mathrm{~g}, 0.5 \mathrm{mmol})$ in ethanol, was added an aqueous solution of $\mathrm{PbCl}_{2}(0.138 \mathrm{~g}, 0.5 \mathrm{mmol})$ and $\mathrm{NaN}_{3}$ (0.0325 g, $0.5 \mathrm{mmol})$ in portions. The resulting reaction mixture was left unperturbed for slow evaporation of the solvent. After 7 days, crystals of 1 were obtained. Yield: 70\% (0.0166 g). Anal. Calc. for $\mathrm{C}_{12} \mathrm{H}_{9} \mathrm{~N}_{7} \mathrm{OPb}(1)$ : C, 30.4; $\mathrm{H}, 1.9$; $\mathrm{N}, 20.7$. Found: $\mathrm{C}, 31.0 ; \mathrm{H}, 2.0 ; \mathrm{N}, 21.8 \%$. IR $\left(\mathrm{KBr} \mathrm{cm} \mathrm{cm}^{-1}\right)$ selected bands: $\nu=\mathrm{CH}$ b (oop): $669(\mathrm{~m})$ and $775(\mathrm{~m}) ; \mathrm{CH}$ b: 1317 (m); CCst: $1458(\mathrm{~m}) ; \mathrm{C}=\mathrm{N}$ st: 1495 and $1584(\mathrm{~m})$; C-O st (Ligand) 1646; N-NN st: 2012 (s); CH st: 3067 (w), and OH st: 3448 (w) $\mathrm{cm}^{-1}$.

\subsection{Synthesis of $\left[\mathrm{Pb}_{2}\left(\mathrm{HL}^{2}\right)_{2}\left(\mathrm{NO}_{3}\right)_{4}\right](2)$ and $\left[\mathrm{Pb}\left(\mathrm{HL}^{2}\right) \mathrm{I}_{2}\right](3)$}

Compounds 2-3 were prepared similarly using the same stoichiometry and reaction condition except that 2-acetyl-pyridylnicotinoylhydrazone $(0.120 \mathrm{~g}, 0.5 \mathrm{mmol})$ instead of 2 -formylpyridyl-nicotinoylhydrazone and $\mathrm{Pb}\left(\mathrm{NO}_{3}\right)_{2}(0.165 \mathrm{~g}, 0.1 \mathrm{mmol})$, $\mathrm{PbI}_{2}$ (0.230 g, $0.5 \mathrm{mmol}$ ), instead of $\mathrm{PbCl}_{2}$ was used.

Compound 2. Yield: $80 \% \quad(0.228$ g). Anal. Calc. $\mathrm{C}_{13} \mathrm{H}_{12} \mathrm{~N}_{6} \mathrm{O}_{7} \mathrm{~Pb}$ (2): C, 27.3; H, 2.1; N, 14.7. Found: C, 31.0; $\mathrm{H}, 2.0 ; \mathrm{N}, 21.8 \%$. IR ( $\left.\mathrm{KBr} \mathrm{cm}^{-1}\right)$ selected bands: $\nu=\mathrm{CH} \mathrm{b}$ (oop):

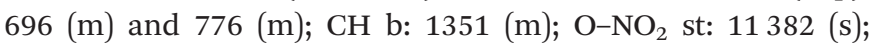
$\mathrm{C}=\mathrm{N}$ st: 1467 and $1589(\mathrm{~m})$; C-O st (Ligand) 1634; CH st: 3073 (w), NH st: 3205 (w) and OH st: $3431(w) \mathrm{cm}^{-1}$.

Compound 3. Yield: $60 \%(0.137 \mathrm{~g})$. Anal. Calc. for $\mathrm{C}_{12} \mathrm{H}_{9} \mathrm{~N}_{7} \mathrm{OPb}(3)$ : C, 22.3; H, 1.7; N, 8.0. Found: C, 22.0; H, 1.9; $\mathrm{N}, 8.1 \%$. IR ( $\left.\mathrm{KBr} \mathrm{cm}^{-1}\right)$ selected bands: $\nu=\mathrm{CH} \mathrm{b}$ (oop): $662(\mathrm{~m})$ and 777 (m); CH b: 1325 (m); CCst: 1461 (m); C=N st: 1501 and $1582(\mathrm{~m})$; C-O st (Ligand) 1649; CH st: 3043 (w), NH st: 3219 (w) and $\mathrm{OH}$ st: $3446(\mathrm{w}) \mathrm{cm}^{-1}$.

\subsection{Synthesis of $\left[\mathrm{Pb}\left(\mathrm{L}^{3}\right)(\mathrm{OAc})\right](4)$}

Compound 4 was prepared similarly using the same stoichiometry and reaction condition except that 2-acetyl-pyridyl-isonicotinoylhydrazone $(0.120 \mathrm{~g}, 0.5 \mathrm{mmol})$ instead of 2-formylpyridyl-nicotinoylhydrazone and $\mathrm{Pb}\left(\mathrm{CH}_{3} \mathrm{COO}\right)_{2} \cdot 3 \mathrm{H}_{2} \mathrm{O}(0.165 \mathrm{~g}$, $0.1 \mathrm{mmol}$ ) instead of $\mathrm{PbCl}_{2}$ was used.

Compound 4. Yield: $84 \% \quad(0.212$ g). Anal. Calc. $\mathrm{C}_{15} \mathrm{H}_{14} \mathrm{~N}_{4} \mathrm{O}_{3} \mathrm{~Pb}$ (4): C, 35.6; H, 2.8; N, 11.1. Found: C, 36.0; $\mathrm{H}, 3.0 ; \mathrm{N}, 11.3 \%$. IR ( $\left.\mathrm{KBr} \mathrm{cm}^{-1}\right)$ selected bands: $\nu=\mathrm{CH} \mathrm{b}$ (oop): $664(\mathrm{~m})$ and $786(\mathrm{~m})$; $\mathrm{CH}$ b: $1326(\mathrm{~m})$; CCst: $1457(\mathrm{~m}) ; \mathrm{C}=\mathrm{N}$ st: 1507 and 1573 (m); C-O st (Ligand) 1648; O-CO st: 1742 (s); CH st: $3096(w)$, and $\mathrm{OH}$ st: $3446(\mathrm{w}) \mathrm{cm}^{-1}$. 


\subsection{X-ray crystallography}

A single crystal of compound 1, suitable for X-ray analysis, was used for intensity data collection on a Nonius Kappa CCD FR590 diffractometer with mirror-monochromatized Mo-K $\alpha$ radiation $(\lambda=0.71073 \AA)$. The data set for compound 2 was collected on a Bruker Smart APEX CCD diffractometer using graphite-monochromated Mo-K $\alpha$ radiation $(\lambda=0.71073 \AA)$. The data set for compound $\mathbf{3}$ and $\mathbf{4}$ were collected on a Bruker AXS diffractometer with mirror-monochromatized Mo-K $\alpha$ radiation $(\lambda=0.71073 \AA)$. All data collections were performed at different temperatures (100-300 K). The structures of all compounds were determined by direct methods and refined by full-matrix least-squares procedures using the SHELXTL package. ${ }^{14}$ All the hydrogen atoms were fixed in calculated positions except those that were detected in the Fourier map. The molecular structure plots were prepared with Mercury. ${ }^{15}$ The details of the crystal parameters, data collection and refinements for all the complexes are summarized in Table 1. Tables S1-S4 (ESI $\dagger$ ) contain the coordination bond distances and angles of the structures reported. Further details are available from the Cambridge Crystallographic Centre with quotation numbers CCDC 1474989 and 1480033-1480035.

\subsection{Theoretical methods}

The geometries of the complexes included in this study were computed at the BP86-D3/def2-TZVP level of theory using the crystallographic coordinates within the TURBOMOLE program. ${ }^{16}$ This level of theory that includes the latest available dispersion correction (D3) is adequate for studying noncovalent interactions dominated by dispersion effects like $\pi$-stacking. The basis set superposition error for the calculation of interaction energies has been corrected using the counter- poise method. ${ }^{17}$ The "atoms-in-molecules" (AIM) ${ }^{18}$ analysis of the electron density has been performed at the same level of theory using the AIMAll program. ${ }^{19}$

\section{Results and discussion}

\subsection{Synthesis and spectroscopy}

The compounds have been synthesized as described in the Experimental section and the reaction pathways are sketched in Scheme 1.

The ligands are expected to exhibit keto-enol tautomerism, and the amide proton can be dissociated through enolization, as observed in compounds $\mathbf{1}$ and $\mathbf{4}$. The IR spectrum of the ligands exhibits two bands in the regions 3205 and $1660 \mathrm{~cm}^{-1}$ due to $\nu(\mathrm{N}-\mathrm{H})$ and $\nu(\mathrm{C}=\mathrm{O})$ stretching, respectively. The free ligand amide $\mathrm{N}-\mathrm{H}$ and $\mathrm{C}=\mathrm{O}$ stretching vibrations are not observed in the IR spectrum of compounds $\mathbf{1}$ and $\mathbf{4}$, but these compounds exhibit a strong absorption band at $1630-1640 \mathrm{~cm}^{-1}$, not observed in the free ligand, which is due to the conjugated $\mathrm{C}=\mathrm{N}-\mathrm{N}=\mathrm{C}-\mathrm{O}$ moiety. Therefore in these compounds the deprotonated ligands are in the enolate form. By contrast the IR spectra of 2 and 3, where the amide $\mathrm{N}$-atom is not deprotonated, exhibit both the amide and $\mathrm{C}=\mathrm{O}$ vibrations and there is no peak characteristic of the deprotonated ligand.

\subsection{Crystal structures of 1-4}

$\left[\mathbf{P b}_{2}\left(\mathbf{L}^{\mathbf{1}}\right)_{2}\left(\mathbf{N}_{3}\right)_{2}\right](\mathbf{1})$. Complex $\mathbf{1}$ crystallizes in the triclinic $P \overline{1}$ space group and consists of a dinuclear metallacycle complex molecule (Fig. 1) with the asymmetric unit containing one-half of the metallacycle unit. Significant structural parameters are

Table 1 Crystal data and structure refinements for compounds 1-4

\begin{tabular}{|c|c|c|c|c|}
\hline Compound & 1 & 2 & 3 & 4 \\
\hline Formula & $\mathrm{C}_{24} \mathrm{H}_{18} \mathrm{~N}_{14} \mathrm{O}_{2} \mathrm{~Pb}_{2}$ & $\mathrm{C}_{26} \mathrm{H}_{24} \mathrm{~N}_{12} \mathrm{O}_{14} \mathrm{~Pb}_{2}$ & $\mathrm{C}_{13} \mathrm{H}_{12} \mathrm{I}_{2} \mathrm{~N}_{4} \mathrm{OPb}$ & $\mathrm{C}_{15} \mathrm{H}_{14} \mathrm{~N}_{4} \mathrm{O}_{3} \mathrm{~Pb}$ \\
\hline Fw & 948.92 & 1142.96 & 701.26 & 505.49 \\
\hline Crystal system & Triclinic & Triclinic & Monoclinic & Monoclinic \\
\hline Space group & $P \overline{1}$ & $P \overline{1}$ & $P 2_{1} / n$ & $P 2_{1} / n$ \\
\hline$a(\AA)$ & $5.834(7)$ & $9.0862(4)$ & $8.0385(12)$ & $7.4569(15)$ \\
\hline$b(\AA)$ & $8.133(4)$ & $9.3122(4)$ & $16.069(2)$ & $13.319(3)$ \\
\hline$c(\AA)$ & $14.800(4)$ & $11.5175(5)$ & $13.0637(19)$ & $15.894(4)$ \\
\hline$\alpha\left({ }^{\circ}\right)$ & $85.65(4)$ & $84.905(1)$ & 90 & 90 \\
\hline$\beta\left({ }^{\circ}\right)$ & $81.87(10)$ & $72.809(1)$ & $97.536(4)$ & $98.541(7)$ \\
\hline$\gamma\left({ }^{\circ}\right)$ & $70.41(7)$ & $62.775(1)$ & 90 & 90 \\
\hline$V\left(\AA^{3}\right)$ & $654.6(9)$ & $826.61(6)$ & $1672.9(4)$ & 1561.1(6) \\
\hline Temp (K) & $293(2)$ & $100(2)$ & $179(2)$ & $300(2)$ \\
\hline$Z$ & 1 & 1 & 4 & 4 \\
\hline$D_{\mathrm{c}}\left(\mathrm{g} \mathrm{cm}^{-3}\right)$ & 2.412 & 2.063 & 2.784 & 2.151 \\
\hline$\mu\left(\mathrm{mm}^{-1}\right)$ & 12.892 & 10.259 & 13.779 & 10.827 \\
\hline No. reflections & 2859 & 14331 & 3641 & 9580 \\
\hline Reflecs $I>2 \sigma(I)$ & 2383 & 3973 & 2857 & 2718 \\
\hline$R_{\text {int }}$ & 0.0438 & 0.0196 & 0.0332 & 0.0308 \\
\hline$F(000)$ & 442 & 540 & 1256 & 952 \\
\hline$R_{1}(I>2 \sigma(I))$ & 0.055 & 0.0198 & 0.0507 & 0.0560 \\
\hline $\mathrm{w} R$ (all data) & 0.1073 & 0.0484 & 0.0731 & 0.0704 \\
\hline GOF & 1.084 & 1.079 & 1.046 & 1.060 \\
\hline
\end{tabular}

$R_{1}=\sum\left[\left|F_{\mathrm{o}}\right|-\left|F_{\mathrm{c}}\right| / \sum\left|F_{\mathrm{o}}\right|\right], \mathrm{w} R_{2}=\left\{\left[\sum \mathrm{w}\left(\left|F_{\mathrm{o}}{ }^{2}-F_{\mathrm{c}}{ }^{2}\right|\right)^{2}\right] /\left[\sum \mathrm{w}\left(F_{\mathrm{o}}{ }^{2}\right)^{2}\right\}\right]^{1 / 2}$. 


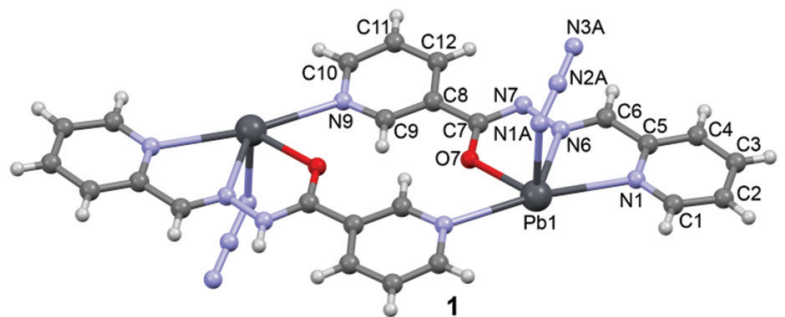

Fig. 1 X-ray molecular structure of 1 with the atom numbering scheme.

given in Table S1. $\dagger$ The structure of the molecule shows that each mononegative ligand $\left(\mathrm{L}^{1}\right)$ binds to the $\mathrm{Pb}(\mathrm{II})$ center via $\mathrm{N}, \mathrm{N}, \mathrm{O}-\mathrm{donor}$ atoms, resulting in two five membered chelate rings. The other two coordination sites around $\mathrm{Pb}$ (II) are occupied by the axial azide ligand and the pyridine $\mathrm{N}$ atom of the other nicotinohydrazide ligand, thus generating the metallacycle. It is also worth stressing that the bonding parameters are in good agreement with the coordinating pattern of a $\mathrm{C}=\mathrm{N}-\mathrm{N}=\mathrm{C}-\mathrm{O}$ moiety via the enolate form: $\mathrm{C} 6-\mathrm{N} 6[1.27(1) \AA]$, N6-N7 [1.36(1) ̊]], N7-C7 [1.32(1) $⿱]$ ] and C7-O7 [1.28(1)] bond distances.

In the crystal structure of 1 the $\mathrm{Pb}^{2+}$ ion is fivefold-coordinated by four atoms of the chelating ligands $\mathrm{L}^{1}$ (N1, N6, $\mathrm{N}^{\mathrm{i}}$, and $\mathrm{O} 1 ; \mathrm{i}=-x, 2-y, 2-z$ ), and a nitrogen atom (N1A) of the azido ligand. All bonds are basically concentrated on one hemisphere of the coordination sphere, thus leaving a large gap on the $\mathrm{Pb}^{2+}$ ion, which enables close approach of a second azide nitrogen atom (N3A) from the adjacent complex. These $\mathrm{Pb} 1 \cdots \mathrm{N} 3 \mathrm{~A}$ contacts further interconnect the metallacycles into a polymeric chain in the solid state (Fig. 2).

$\left[\mathrm{Pb}_{2}\left(\mathrm{HL}^{2}\right)_{2}\left(\mathrm{NO}_{3}\right)_{4}\right]$ (2). Complex 2 crystallizes in the triclinic $P \overline{1}$ space group and consists of a dinuclear metallacycle complex molecule (Fig. 3) with the asymmetric unit containing one-half of the metallacycle unit. Significant structural parameters are given in Table S2. $\dagger$ The structure of the molecule (Fig. 3) shows that each neutral ligand $\left(\mathrm{HL}^{2}\right)$ binds to the $\mathrm{Pb}(\mathrm{II})$ center via $\mathrm{N}, \mathrm{N}, \mathrm{O}-$ donor atoms resulting in two five membered chelate rings. The other three coordination sites around $\mathrm{Pb}(\mathrm{II})$ are occupied by one bidentate and two bridging nitrato ligands forming the metallacycle. The bonding parameters are in good agreement with the coordinating pattern of a $\mathrm{C}=\mathrm{N}-$

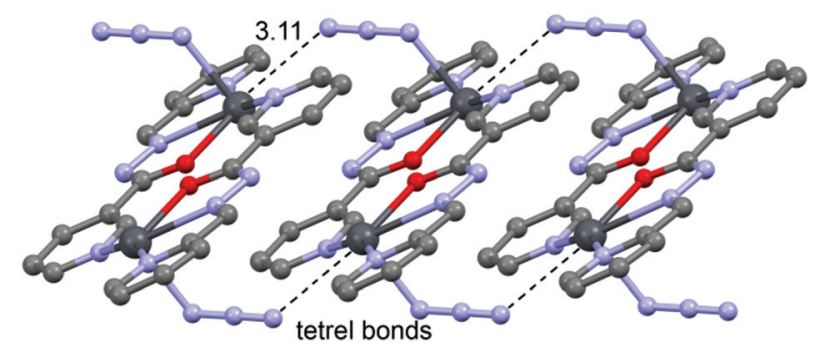

Fig. 2 Chains in the crystal structure of 1 . Tetrel bonds $\mathrm{Pb} \cdots \mathrm{N}$ are shown as dashed lines. Distance in $\AA$.

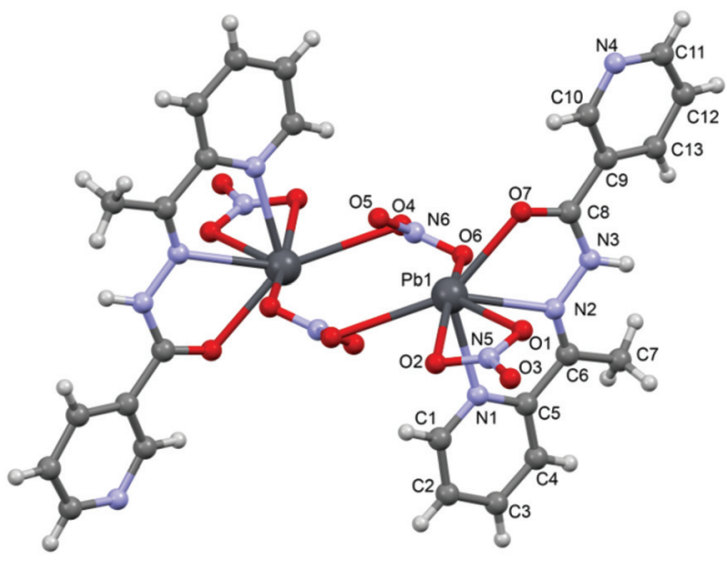

Fig. 3 Perspective view of the molecular structure of 2 with the atom numbering scheme.

$\mathrm{NH}-\mathrm{C}=\mathrm{O}$ moiety: $\mathrm{C} 6-\mathrm{N} 2[1.288(5) \AA], \mathrm{N} 2-\mathrm{N} 3 \quad[1.386(4) \AA]$,

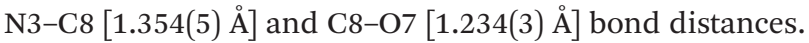

In the crystal structure of 2 the $\mathrm{Pb}^{2+}$ ion is sevenfold-coordinated by three atoms of the chelating ligands $\mathrm{HL}^{2}(\mathrm{~N} 1, \mathrm{~N} 2$ and $\mathrm{O} 7)$, and four oxygen atoms of the nitrato ligands (O1, O2, $\mathrm{O} 4{ }^{\mathrm{ii}}$ and $\mathrm{O} 6$, ii $\left.=2-x, 1-y,-z\right)$. Remarkably, all seven coordination bonds are concentrated on one hemisphere of the coordination sphere, thus leaving a large gap on the $\mathrm{Pb}^{2+}$ ion, which enables close approach of the nitrogen atom (N4) of the uncoordinated pyridine ring of the ligand belonging to a neighbouring complex. These $\mathrm{Pb} 1 \cdots \mathrm{N} 6$ contacts interconnect the metallacycles into a polymeric chain in the solid state (Fig. 4).

$\left[\mathbf{P b}\left(\mathbf{H L}^{2}\right) \mathbf{I}_{2}\right]$ (3). Complex 3 crystallizes in the monoclinic $P 2_{1} / n$ space group and consists of a mononuclear complex molecule (Fig. 5). Significant structural parameters are given in Table S3. $\dagger$ The structure of the molecule (Fig. 3) shows that the neutral ligand $\left(\mathrm{HL}^{2}\right)$ binds to the $\mathrm{Pb}$ (II) center via $\mathrm{N}, \mathrm{N}, \mathrm{O}-$ donor atoms, resulting in two five membered chelate rings. The other two coordination sites around $\mathrm{Pb}$ (II) are occupied by the iodide ligands. The bonding parameters are in good agreement with the coordinating pattern of a $\mathrm{C}=\mathrm{N}-\mathrm{NH}-\mathrm{C}=\mathrm{O}$ moiety: C2-N2 [1.271(9) $\AA], \quad \mathrm{N} 2-\mathrm{N} 1 \quad[1.389(9) \AA]$, N1-C1 [1.366(9) $\AA]$ and C1-O1 [1.212(8) $\AA]$ bond distances.

In the crystal structure of 3 the $\mathrm{Pb}^{2+}$ ion is fivefold-coordinated by three atoms of the chelating ligands $\mathrm{HL}^{2}(\mathrm{~N} 1, \mathrm{~N} 3$ and O1), and two iodide counterions. Clearly, all five coordi-

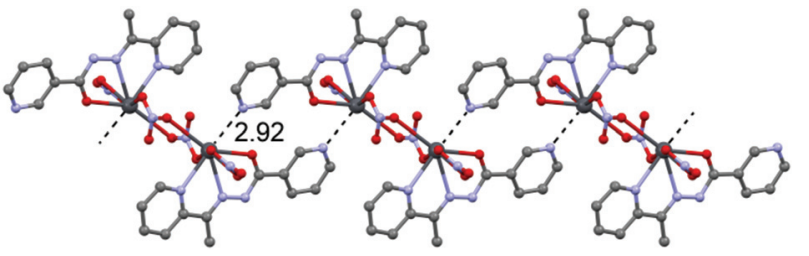

Fig. 4 Chains in the crystal structure of 2. Tetrel bonds $\mathrm{Pb} \cdots \mathrm{N}$ are shown as dashed lines. Distance in $\AA$. 


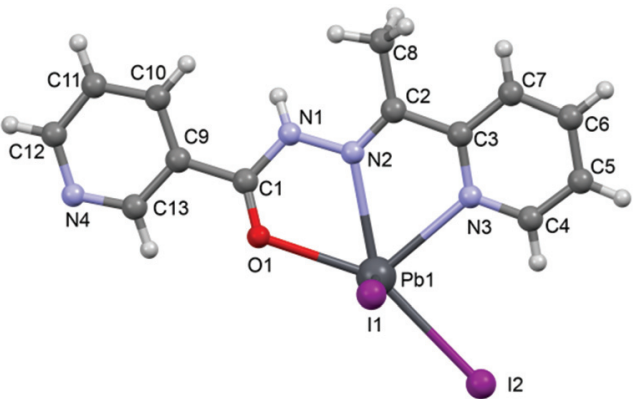

Fig. 5 Perspective view of the molecular structure of 3 with the atom numbering scheme.

nation bonds are concentrated on less than one hemisphere of the coordination sphere, thus leaving a large gap on the $\mathrm{Pb}^{2+}$ ion, which enables close approach of the nitrogen atom (N4) of the uncoordinated pyridine ring of the ligand belonging to a neighbouring complex. These Pb1 $\cdots \mathrm{N} 4$ tetrel bonding contacts control the formation of self-assembled dimers (see Fig. 6) in the solid state structure. The coordination bonds and the noncovalent $\mathrm{Pb} 1 \cdots \mathrm{N} 4$ contact fulfil one half of the coordination sphere. The other hemisphere is used to establish chelate ring $\cdots \pi$ stacking interactions that connect and propagate the self-assembled dimers in the solid state (see Fig. 6) interactions.

$\left[\mathrm{Pb}\left(\mathrm{L}^{3}\right)(\mathrm{OAc})\right]$ (4). Complex 4 crystallizes in the monoclinic $P 2_{1} / n$ space group and consists of a mononuclear complex molecule (Fig. 7). Significant structural parameters are given in Table S4. $\dagger$ The structure of the molecule (Fig. 7) shows that the anionic ligand $\left(\mathrm{L}^{3}\right)$ binds to the $\mathrm{Pb}(\mathrm{II})$ center via $\mathrm{N}, \mathrm{N}, \mathrm{O}-$ donor atoms, resulting in two five membered chelate rings. The other coordination site around $\mathrm{Pb}$ (II) is occupied by the $\mathrm{O}$ atom of the acetate co-ligand. The bonding parameters are in good agreement with the coordinating pattern of a $\mathrm{C}=\mathrm{N}-$ $\mathrm{N}=\mathrm{C}-\mathrm{O}$ moiety via the enolate form: C4-N1 [1.300(10) $\mathrm{A}]$, N2-

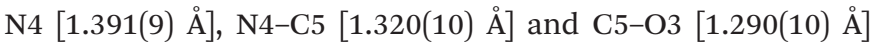
bond distances.

In the crystal structure of 4 the $\mathrm{Pb}^{2+}$ ion is only fourfold-coordinated by three atoms of the chelating ligands $\mathrm{L}^{3}(\mathrm{~N} 1, \mathrm{~N} 3$ and O3), and one atom (O1) from the acetate. Clearly, all four coordination bonds are concentrated on less than one hemi-

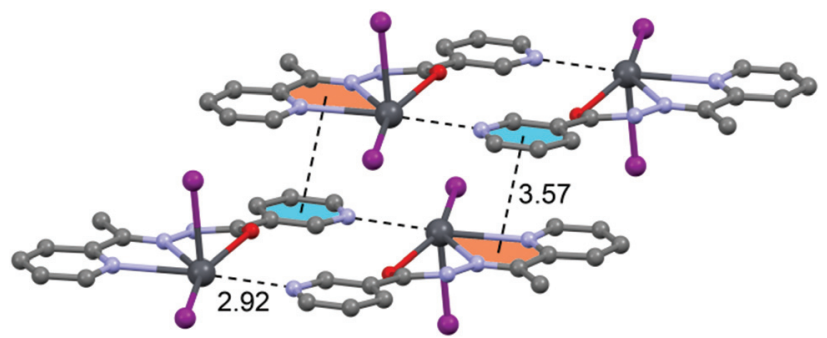

Fig. 6 Self-assembled dimers observed in the crystal structure of 3 . Tetrel bonds $\mathrm{Pb} \cdots \mathrm{N}$ and chelate ring $\cdots \pi$ interactions are shown as dashed lines. Distance in $\AA$.

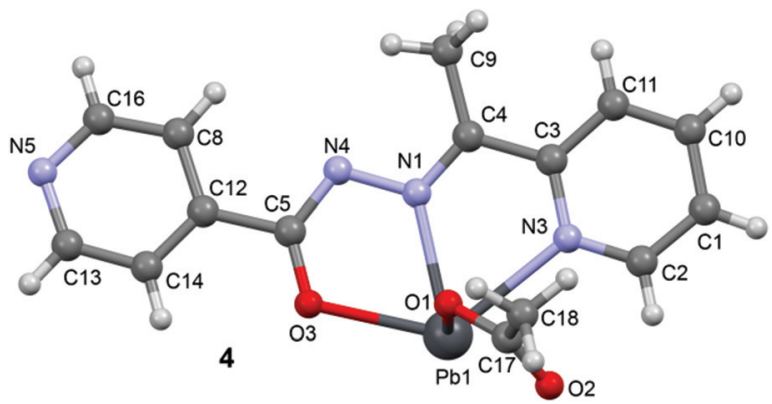

Fig. 7 Perspective view of the molecular structure of 4 with the atom numbering scheme.

sphere of the coordination sphere, thus leaving a large gap on the $\mathrm{Pb}^{2+}$ ion, which enables a close interaction with the nitrogen atom (N5) of the uncoordinated pyridine ring of the ligand belonging to another complex. Moreover, opposite to the axial acetate ligand this compound forms a self-assembled $\pi$-stacked supramolecular complex. The antiparallel arrangement of the complexes allows the formation of two symmetrically related $\pi-\pi$ interactions between the coordinated pyridine ring of one ligand and the uncoordinated pyridine ring of the other ligand. This self-assembled dimer establishes four equivalent $\mathrm{Pb} 1 \cdots \mathrm{N} 5$ tetrel bonding contacts, two as donor and two as acceptor (see Fig. 8) controlling the final 3D architecture of this compound in solid state structure.

In addition to the tetrel bonding and stacking interactions described above for compounds 1-4, H-bonding interactions are also important, especially in complexes with neutral ligands ( 2 and 3 ). This is due to the presence of the highly acidic CONH amide proton. The coordination of the amide oxygen atom of the ligand to $\mathrm{Pb}^{2+}$ dramatically increases the $\mathrm{H}$-bond donor ability of the amide proton. Consequently both compounds present $\mathrm{N}-\mathrm{H} \cdots \mathrm{X}(\mathrm{X}=\mathrm{O}, \mathrm{I})$ interactions that govern the formation of relevant supramolecular assemblies (1D chains) in their solid state structures, as depicted in Fig. 9.

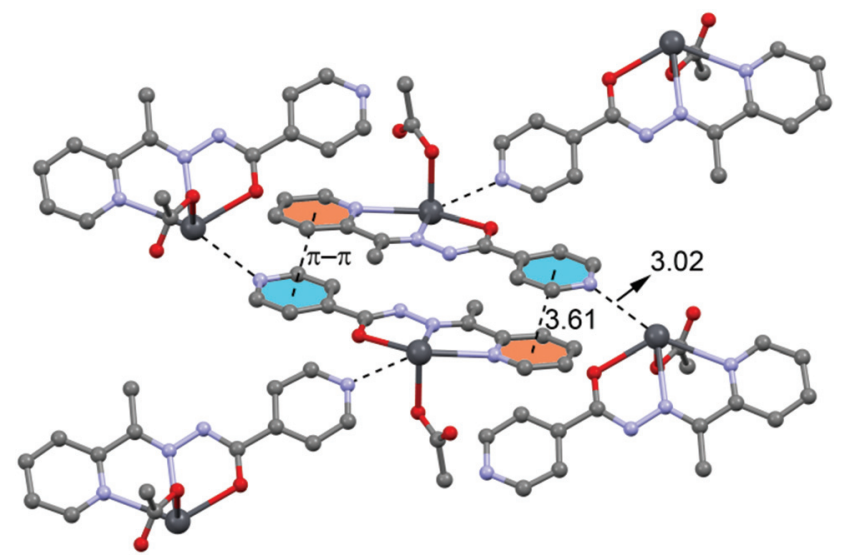

Fig. 8 Self-assembled dimer observed in the crystal structure of 4 and its interaction with neighbouring molecules. Tetrel bonds $\mathrm{Pb} \cdots \mathrm{N}$ and $\pi \cdots \pi$ interactions are shown as dashed lines. Distances in $\AA$. 

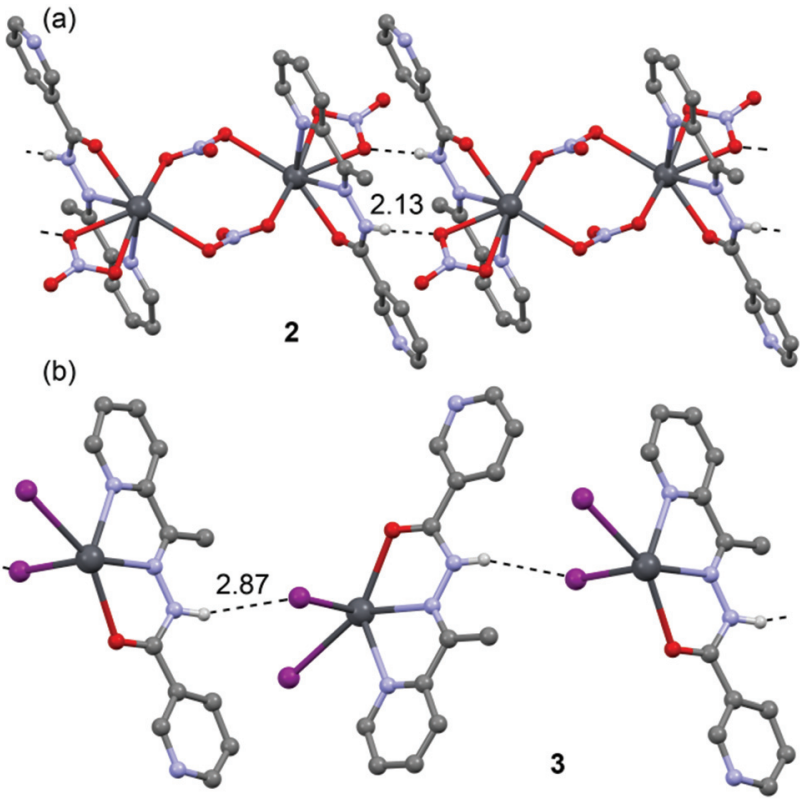

Fig. $9 \mathrm{~N}-\mathrm{H} \cdots \mathrm{O} / \mathrm{l} \mathrm{H}$-bonded chains in the crystal structure of 2 (a) and 3 (b). $\mathrm{H}$-bonds are shown as dashed lines. Distances in $\AA$.

\subsection{Theoretical study of the supramolecular assemblies}

We have focused the theoretical study on the analysis of the remarkable supramolecular assemblies observed in the solid state of complexes 1-4, directing our attention to the more unconventional, tetrel bonding and stacking interactions. Particularly in compounds $\mathbf{1}$ and $\mathbf{2}$ we have analysed the $\mathrm{Pb} \cdots \mathrm{N}$ interactions that have a prominent role in the formation of infinite 1D chains in the solid state. Moreover, in compounds 3 and 4 we have analysed the combination of $\pi$-stacking interactions (chelate $-\pi$ in 3 and $\pi-\pi$ in 4 ) and tetrel bonding interactions that control the formation of self-assembled dimers.

In order to analyse the donor-acceptor properties of the $\mathrm{Pb}$ (II) complexes ligand (in both enolate and neutral forms), we have computed the molecular electrostatic potential (MEP) surface of compound $\mathbf{1}$ (enolate) and $\mathbf{3}$ (neutral), which are represented in Fig. 10 and 11. In the MEP surface of compound 1 the most positive part corresponds to the metal center and, unexpectedly, the most negative part is located at the $\mathrm{N}$ atom of the pyridine instead of the $\mathrm{N}_{3}{ }^{-}$ligand, thus explaining the formation of the dinuclear metallacycle in 1. In complex 4, where the ligand is also in the enolate form does not form the metallacycle due to the different directionality of the pyridine N-atom (para). An interesting aspect of the MEP surface is that the MEP values over the pyridine ring centers present opposite signs (see Fig. 10b). Therefore the enolate form of the ligand is well prepared to form strong $\pi-\pi$ interactions (electrostatically assisted) between the coordinated and uncoordinated pyridine rings, as observed in 4 (see Fig. 8).

The MEP surface of a complex having the neutral form of the ligand is shown in Fig. 11. It exhibits significant differences with respect to the enolate form. First, the most positive

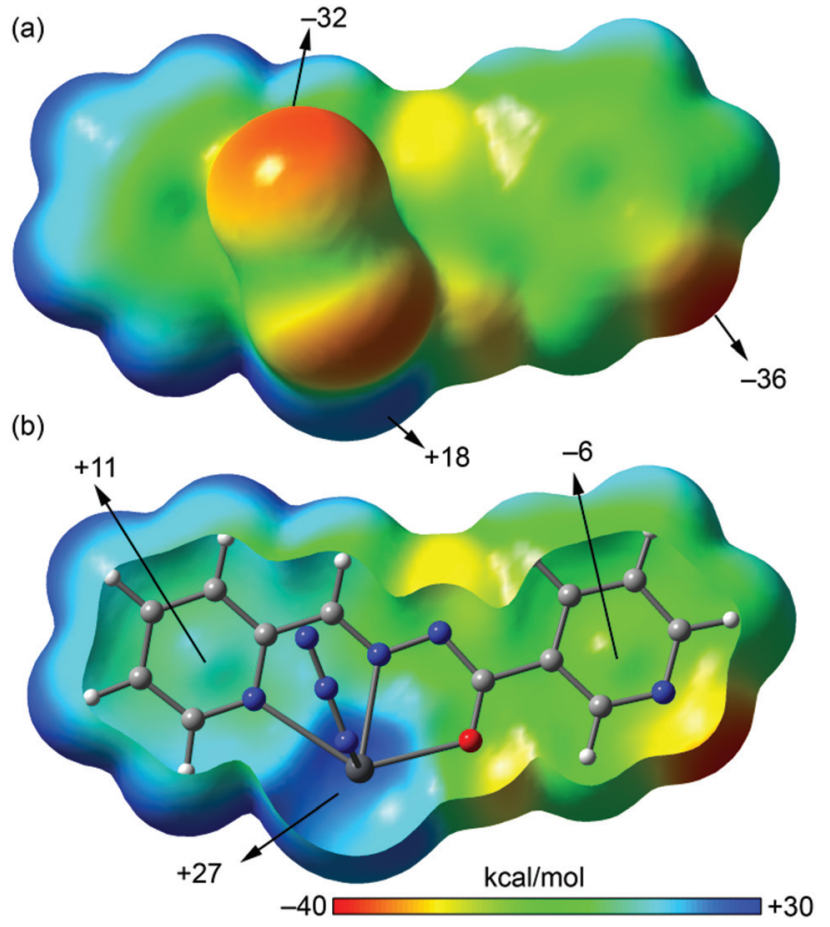

Fig. 10 MEP plotted onto the van der Waals surface [close (a) and $Z$-clipped (b)] of a half of compound 1 computed at the BP86/def2-SVP level of theory. The MEP values at selected points of the surface are indicated.

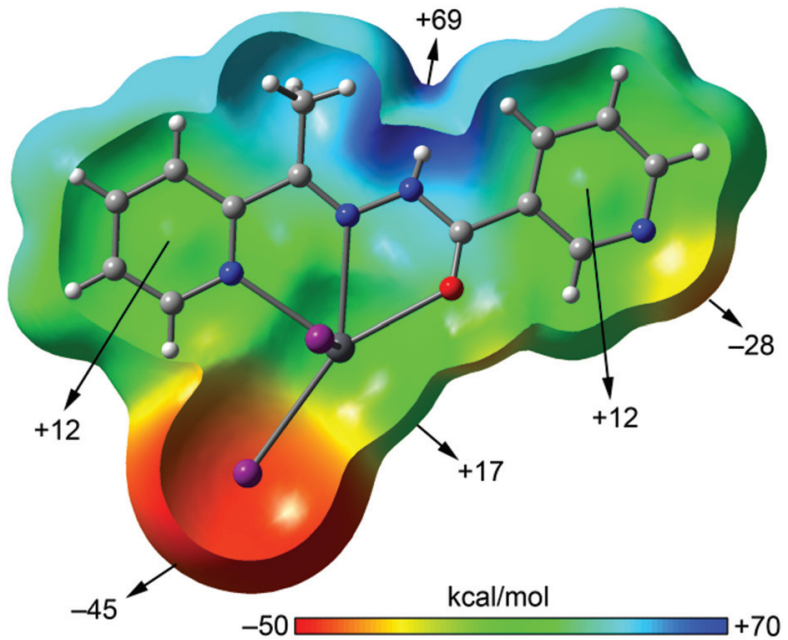

Fig. 11 MEP plotted onto the van der Waals surface (Z-clipped) of compound 3 computed at the BP86/def2-SVP level of theory. The MEP values at selected points of the surface are indicated.

value is located on the amide $\mathrm{N}-\mathrm{H}$ and the most negative in the iodide ligand, thus explaining the formation of $\mathrm{H}$-bonded chains in the solid state. Another significant difference is the behaviour regarding the MEP values over the pyridine rings, since both are positive. Finally, the MEP value on the metal center is positive and that at the uncoordinated pyridine $\mathrm{N}$-atom is negative and smaller in absolute value than the one 
observed for the enolate form. The directionality of the lone pair of the uncoordinated pyridine and the $\mathrm{Pb} \sigma$-hole is ideal for the formation of self-assembled dimers as observed in the solid state of 3 (see Fig. 6).

An energetic DFT study was undertaken to examine more closely the nature of the $\mathrm{Pb} \cdots \mathrm{N}$ interactions observed in the structures of $\mathbf{1 - 4}$. In $\mathbf{1}$ we analysed the $\mathrm{Pb} 1 \cdots \mathrm{N} 3 \mathrm{~A}$ contacts responsible for interconnection of the metallacycles into infinite chains (see Fig. 2). The interaction energy (Fig. 12a) is large and negative $\left(\Delta E_{1}=-40.4 \mathrm{kcal} \mathrm{mol}^{-1}\right)$ and thus indicates a very strong binding motif in the crystal structure. Similarly, in compound 2 we have evaluated the $\mathrm{Pb} 1 \cdots \mathrm{N} 6$ contacts responsible for interconnection of the metallacycles into infinite chains (Fig. 4). In this complex the interaction energy is considerably less negative $\left(\Delta E_{2}=-19.8 \mathrm{kcal} \mathrm{mol}^{-1}\right)$, indicating a weaker binding. This is likely due to a combination of two factors. First, there is an additional $\pi$-stacking interaction in the dimer of $\mathbf{1}$ that also contributes to the stabilization of the assembly. Secondly, in compound $\mathbf{1}$ the ligand is in the enolate form, thus favouring the tetrel bonding interaction as anticipated by the MEP analysis. In fact, each $\mathrm{Pb}^{2+}$ metal center is coordinated to three nitrato ligands in 2 that reduce the tetrel bonding donor ability of the $\mathrm{Pb}$ atom. Following the

(a)
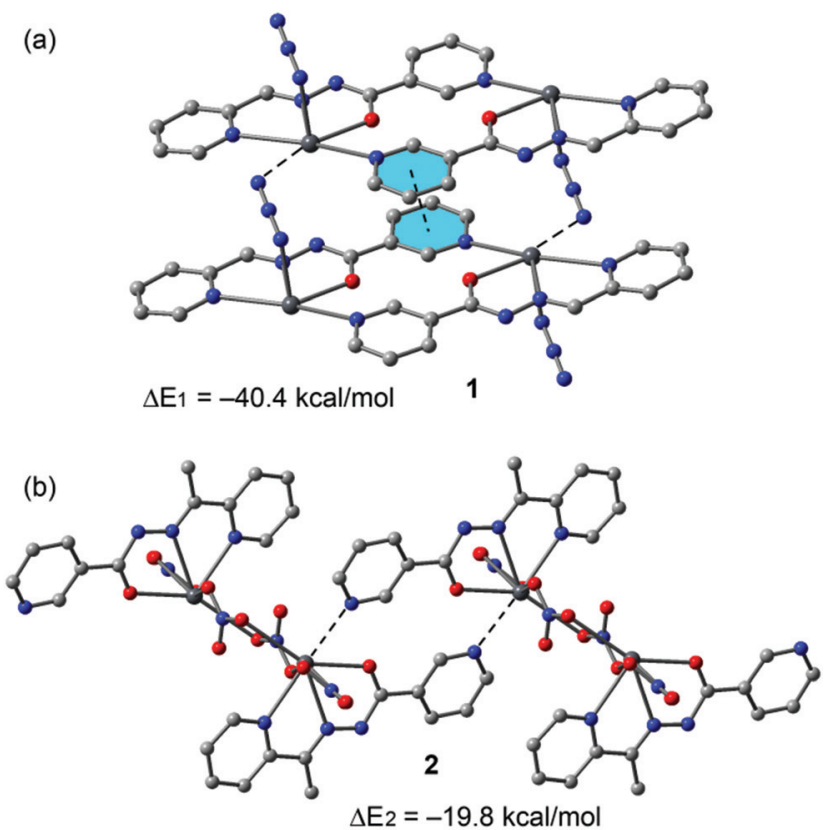

(c)

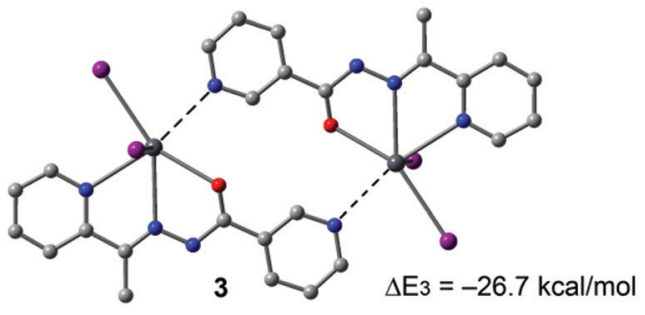

Fig. 12 Interaction energies of tetrel bonded dimers of compounds 1 (a), 2 (b) and 3 (c) computed at the BP86-D3/def2-SVP level of theory. same reasoning, the interaction energy of the dimer observed in the solid state of compound $\mathbf{3}$ (neutral ligand) exhibits an interaction energy $\left(\Delta E_{3}=-26.7 \mathrm{kcal} \mathrm{mol}^{-1}\right)$ that is smaller in absolute value than that of compound 1 (enolate form, $\Delta E_{1}$ ), but larger than $\Delta E_{2}$ (compound 2). The latter is due to the different coordination environment of the $\mathrm{Pb}$, which is coordinated to two iodido ligands in $\mathbf{3}$ and to three nitrato ligands in 2, thus decreasing the $\mathrm{Pb}$ Lewis acidity in $\mathbf{2}$ and, consequently, decreasing the $\mathrm{Pb} \cdots \mathrm{N}$ strength.

In compound $\mathbf{4}$ we have focused the theoretical study on the computation of the energy of the interactions responsible for the formation of the supramolecular assembly shown in Fig. 8 , which are the antiparallel $\pi-\pi$ stacking interaction and the tetrel bonding. The results are gathered in Fig. 13. The interaction energy of the antiparallel p-stacking is very large $\left(\Delta E_{4}=-29.0 \mathrm{kcal} \mathrm{mol}^{-1}\right)$ in agreement with the MEP study that shows opposite signs for the MEP values over the coordinated and uncoordinated pyridine rings. Consequently these electrostatically enhanced $\pi^{+}-\pi^{-}$complexes are very strong binding motifs in the crystal structure. Finally, the interaction energy of the tetrel bond $\left(\Delta E_{5}=-10.5 \mathrm{kcal} \mathrm{mol}^{-1}\right)$ is modest compared to the half of $\Delta E_{1}$ (also enolate form, see Fig. 12a). This is likely due to the additional $\pi-\pi$ interaction observed in the solid state of 1 that also contributes to $\Delta E_{1}$.

Finally, we have used the Bader's theory of "atoms in molecules", which provides an unambiguous definition of chemical bonding, to further describe the noncovalent tetrel bonding interactions described above. The AIM theory has been effectively utilized to characterize a great variety of interactions. ${ }^{20}$

In Fig. 14 we show the AIM analysis of the tetrel bonding complex (a) and the self-assembled $\pi$-stacked dimer of compound 4 (the AIM analyses of compounds 1-3 are included in the ESI, Fig. S1-S3†). The $\mathrm{Pb} \cdots \mathrm{N}$ interaction is confirmed by the presence of a bond $\mathrm{CP}$ and a bond path connecting the $\mathrm{N}$ atom of pyridine to the $\mathrm{Pb}$ atom. It can be also observed two intermolecular $\mathrm{H}$ bonds involving two aromatic $\mathrm{C}-\mathrm{H}$ bonds as acceptors. The density at the bond CP that characterizes the tetrel bond is larger than those observed for the H-bonds, indicating that it is the strongest interaction.

Regarding the $\pi$-stacked dimer (Fig. 14b) It can be observed that the $\pi^{+}-\pi^{-}$interactions are characterized by the presence of several bond (red spheres), ring (red spheres) and cage (green spheres) critical points (CPs). Basically, two bond CPs connect

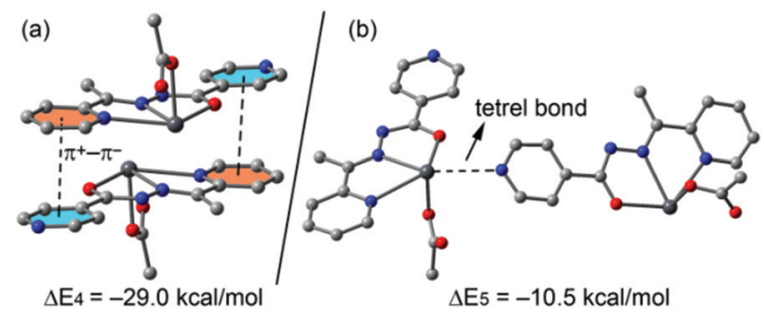

Fig. 13 Interaction energies of $\pi$-stacked (a) and tetrel bonded (b) dimers of compound 4 (computed at the BP86-D3/def2-TZVP level of theory). 


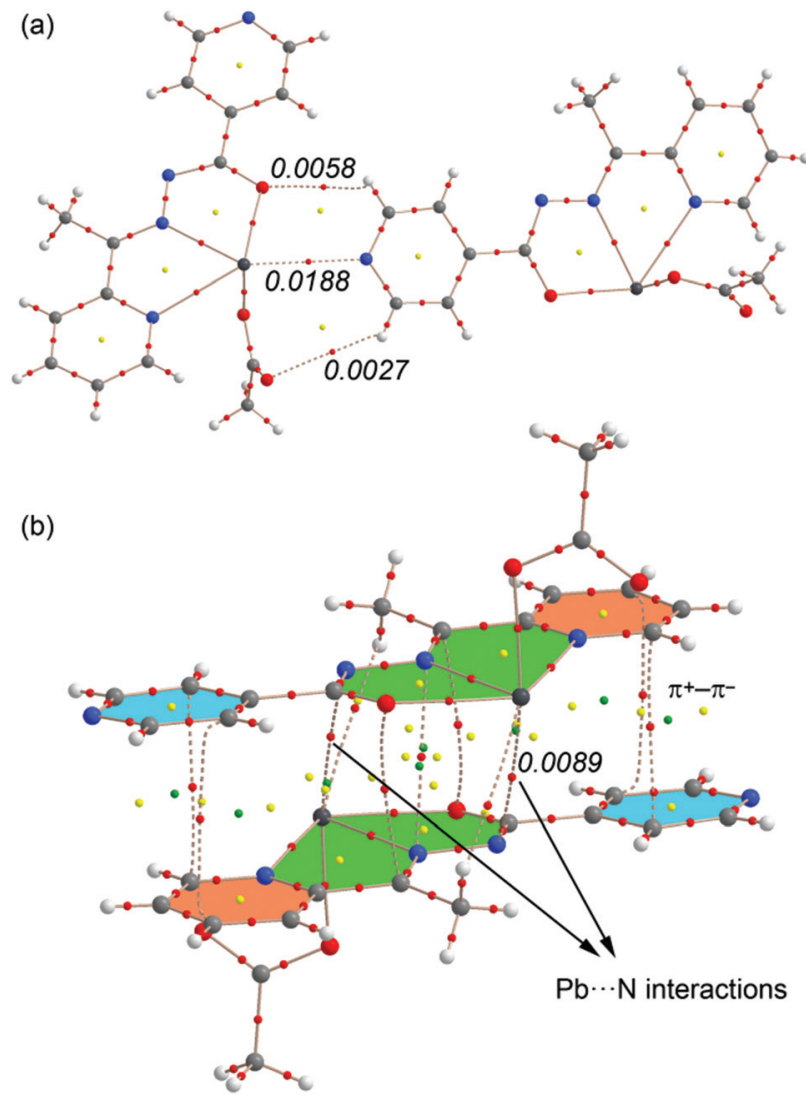

Fig. 14 AIM analyses of two dimers of complex 4. Bond, ring and cage critical points are represented by red, yellow and green spheres, respectively. The bond paths connecting bond critical points are also represented by dashed lines. The value of $\rho(r)$ at the bond CPs is given for some interactions in a.u.

the carbon atoms of one pyridine to two carbon atoms of the other pyridine. The $\pi-\pi$ complex is further characterized by additional CPs that connect the chelate rings. As a consequence of this complicated distribution of bond CPs, several ring and cage CPs are also generated upon complexation due to the formation of supramolecular ring and cages. Remarkably, the AIM reveals the existence of two $\mathrm{Pb} \cdots \mathrm{N}$ contacts that explain the large interaction energy obtained for this dimer (in addition to the electrostatically enhanced $\pi^{+}-\pi^{-}$interactions, see 13a). The value of the Laplacian of the charge density computed at the bond critical points in both assemblies is positive, as is common in closed-shell interactions.

\section{Conclusions}

In conclusion, we report the syntheses and structural characterization of four new $\mathrm{Pb}^{2+}$ complexes with (iso)nicotinohydrazide-based ligands All compounds 1-4 exhibit relevant tetrel bonding interactions in the solid state that have been described and characterized using DFT calculations. The energies associated with the interactions have been computed using DFT calculations. In general, these noncovalent $\mathrm{Pb} \cdots \mathrm{N}$ interactions are strong due to electrostatic effects, as shown by the MEP analysis. Our results might be important to understand the solid state architecture of organic-inorganic materials systems that contain hemidirectionally coordinated $\mathrm{Pb}^{2+}$ metal centers and organic aromatic molecules.

\section{Acknowledgements}

We are grateful to the University of Maragheh for the generous financial support of this research. A. B. and A. F. thank DGICYT of Spain (projects CTQ2014-57393-C2-1-P and CONSOLIDER INGENIO CSD2010-00065, FEDER funds) for funding. We thank the CTI (UIB) for free allocation of computer time. E. M. is grateful to Generalitat de Catalunya (2014SGR1643), Ministerio de Economia y Competividad (projects ENE2012-36368 and SEV2015-0496), and EU's Seventh Framework Programme (IRSES EULANETCERMAT). JTM thanks Tulane University for support of the Tulane X-ray Crystallography Laboratory.

\section{Notes and references}

1 Y. Wang, L. J. Zhou, M. L. Feng and X. Y. Huang, Dalton Trans., 2012, 41, 6689; C. S. Liu, X. S. Shi, J. R. Li, J. J. Wang and X. H. Bu, Cryst. Growth Des., 2006, 6, 656; S. Kitagawa, R. Kitaura and S. Noro, Angew. Chem., Int. Ed., 2004, 43, 2334; S. G. Telfer and R. Kuroda, Coord. Chem. Rev., 2003, 242, 33; S. A. Barnett and N. R. Champness, Coord. Chem. Rev., 2003, 246, 145.

2 Y.-F. Hsu, H.-L. Hu, C.-J. Wu, C.-W. Yeh, D. M. Proserpio and J.-D. Chen, CrystEngComm, 2009, 11, 168.

3 J. Yang, B. Wu, F. Zhuge, J. Liang, C. Jia, Y.-Y. Wang, N. Tang, X.-J. Yang and Q.-Z. Shi, Cryst. Growth Des., 2010, 10, 2331.

4 F. F. B. J. Janssen, L. P. J. Veraart, J. M. M. Smits, R. de Gelder and A. E. Rowan, Cryst. Growth Des., 2011, 11, 4313.

5 G. A. Jeffrey, An Introduction to Hydrogen Bonding, Oxford University Press, Oxford, 1997; Y. Xia, S. Li, B. Wu, Y. Liua and X.-J. Yanga, CrystEngComm, 2011, 13, 5763; P. Dechambenoit, S. Ferlay, M. W. Hosseini and N. Kyritsakas, Chem. Commun., 2007, 4626; W. Li, A. Thirumurugan, P. T. Barton, Z. Lin, S. Henke, H. H.-M. Yeung, M. T. Wharmby, E. G. Bithell, C. J. Howard and A. K. Cheetham, J. Am. Chem. Soc., 2014, 136, 7801; J. M. Roberts, B. M. Fini, A. A. Sarjeant, O. K. Farha, J. T. Hupp and K. A. Scheidt, J. Am. Chem. Soc., 2012, 134, 3334; R. S. Forgan, R. J. Marshall, M. Struckmann, A. B. Bleine, D.-L. Long, M. C. Bernini and D. FairenJimenez, CrystEngComm, 2015, 17, 299; M. Servati-Gargari, G. Mahmoudi, S. R. Batten, V. Stilinović, D. Butler, L. Beauvais, W. S. Kassel, W. G. Dougherty and D. VanDerveer, Cryst. Growth Des., 2015, 15, 1336.

6 P. Politzer, J. S. Murray and T. Clark, Phys. Chem. Chem. Phys., 2013, 15, 11178; A. Bauzá, T. J. Mooibroek and 
A. Frontera, ChemPhysChem, 2015, 16, 2496; A. Bauzá and A. Frontera, Angew. Chem., Int. Ed., 2015, 54, 7340.

7 J. S. Murray, K. E. Riley, P. Politzer and T. Clark, Aust. J. Chem., 2010, 63, 1598; P. Politzer and J. S. Murray, ChemPhysChem, 2013, 14, 278; P. Politzer, J. S. Murray and T. Clark, Phys. Chem. Chem. Phys., 2010, 12, 7748; P. Politzer, K. E. Riley, F. A. Bulat and J. S. Murray, Comput. Theor. Chem., 2012, 998, 2; A. Bauzá, I. Alkorta, A. Frontera and J. Elguero, J. Chem. Theory Comput., 2013, 9, 5201; G. Sánchez-Sanz, C. Trujillo, I. Alkorta and J. Elguero, Phys. Chem. Chem. Phys., 2014, 16, 15900-15909.

8 A. Bauzá, T. J. Mooibroek and A. Frontera, Angew. Chem., Int. Ed., 2013, 52, 12317; S. J. Grabowski, Phys. Chem. Chem. Phys., 2014, 16, 1824; A. Bauzá, T. J. Mooibroek and A. Frontera, Chem. - Eur. J., 2014, 20, 10245; E. C. Escudero-Adán, A. Bauzá, A. Frontera and P. Ballester, ChemPhysChem, 2015, 16, 2530; A. Bauzá, T. J. Mooibroek and A. Frontera, Phys. Chem. Chem. Phys., 2014, 16, 19192; A. Bauzá, T. J. Mooibroek and A. Frontera, Chem. Commun., 2014, 50, 12626; A. Bauzá, T. J. Mooibroek and A. Frontera, Chem. Rec., 2016, 16, 473; J. S. Murray, P. Lane and P. Politzer, J. Mol. Model, 2009, 15, 7239; A. Bundhun, P. Ramasami, J. S. Murray and P. Politzer, J. Mol. Model, 2013, 19, 2739; R. S. Ruoff, T. Emilsson, A. I. Jaman, T. C. Germann and H. S. Gutowsky, J. Chem. Phys., 1992, 96, 3441; R.-D. Urban, G. Rouillé and M. Takami, J. Mol. Struct., 1997, 413-414, 511; I. Alkorta, I. Rozas and J. Elguero, J. Phys. Chem. A, 2001, 105, 743.

9 M. Servati Gargari, V. Stilinović, A. Bauzá, A. Frontera, P. McArdle, D. Van Derveer, S. W. Ng and G. Mahmoudi, Chem. - Eur. J., 2015, 21, 17951-17958.
10 G. Mahmoudi, A. Bauzá and A. Frontera, Dalton Trans., 2016, 45, 4965-4969.

11 L. Shimoni-Livny, J. P. Glusker and C. W. Bock, Inorg. Chem., 1998, 37, 1853; R. L. Davidovich, V. Stavila, D. V. Marinin, E. I. Voit and K. H. Whitmire, Coord. Chem. Rev., 2009, 253, 1316.

12 P. V. Bernhardt, G. J. Wilson, P. C. Sharpe, D. S. Kalinowski and D. R. Richardson, J. Biol. Inorg. Chem., 2008, 13, 107.

13 E.-I. Ochiai, J. Chem. Educ., 1995, 72, 479.

14 G. M. Sheldrick, SHELXTL: Structure Determination Software Suite, Version 6.14, Bruker AXS, Madison, WI, USA, 2003.

15 Mercury 1.4.1, Copyright Cambridge Crystallographic Data Centre, 12 Union Road, Cambridge, CB2 1EZ, UK, 2001-2005.

16 R. Ahlrichs, M. Bär, M. Häser, H. Horn and C. Kölmel, Chem. Phys. Lett., 1989, 162, 165.

17 S. F. Boys and F. Bernardi, Mol. Phys., 1970, 19, 553-566.

18 R. F. W. Bader, Chem. Rev., 1991, 91, 893-928.

19 T. A. Keith, AIMAll (Version 13.05.06), TK Gristmill Software, Overland Park KS, USA, 2013.

20 (a) A. Bauzá and A. Frontera, ChemPhysChem, 2015, 16, 3108-3113; (b) A. Bauzá and A. Frontera, ChemPhysChem, 2015, 16, 3625-3630; (c) A. Bauzá, T. J. Mooibroek and A. Frontera, ChemPhysChem, 2015, 16, 2496-2517; (d) E. C. Escudero-Adán, A. Bauzá, A. Frontera and P. Ballester, ChemPhysChem, 2015, 16, 2530-2533; (e) M. Mirzaei, M. Nikpour, A. Bauza and A. Frontera, ChemPhysChem, 2015, 16, 2260-2266; (f) A. Bauzá and A. Frontera, Chem. Phys. Lett., 2015, 633, 282-286; (g) A. Bauzá and A. Frontera, Angew. Chem., Int. Ed., 2015, 54, 7340-7343. 